\title{
Patriarchy and Gender-Based Violence: Experiences of Female Sex Workers in India
}

\author{
Sharvari Karandikar (Corresponding author) \\ College of Social Work, The Ohio State University \\ 1947 N College Road Columbus, Ohio 43220, USA \\ E-mail: karandikar-chheda.1@osu.edu \\ Caren Frost \\ College of Social Work, University of Utah \\ 395 S, 1500 E Salt Lake City, Utah 84112, USA \\ E-mail: Caren.Frost@socwk.utah.edu \\ Lindsay Gezinski \\ 39 College of Social Work, University of Utah \\ 395 S, 1500 E Salt Lake City, Utah 84112, USA \\ E-mail: Lindsay.Gezinski@socwk.utah.edu
}

Received: January 29, 2014 Accepted: March 19, 2014 Published: March 28, 2014

doi:10.5296/ijsw.v1i1.5011ＵRL: http://dx.doi.org/10.5296/ijsw.v1i1.5011

\begin{abstract}
This qualitative study explored gender-based violence among female sex workers in India. Ten sex workers from Kamathipura, Asia's largest red-light area based in Mumbai, were interviewed. Radical sexual pluralist feminist theory informed data analysis and data interpretation. Results revealed high incidence of gender-based violence with sex workers reporting intense physical and sexual violence and coercion from male partners, pimps and clients. The exposure to violence significantly contributed to sex workers' inability to negotiate safe sex, leading to high HIV risks. The research highlights the lack of a sound policy on sex work in India and the drawbacks of the criminalization of sex work.
\end{abstract}


Keywords: Sex work, India, Gender-based violence, HIV/AIDS

\section{Introduction}

The purpose of this study was to explore the experiences of female commercial sex workers in Kamathipura, Mumbai, India. Kamathipura is located in Mumbai, India and is Asia's largest red-light area, consisting of approximately 15,000 male, female and transgender sex workers, who are either brothel-based or street-based. Almost 90 percent of the sex workers in Kamathipura have some form of sexually transmitted infection at any given point of time (Legislative Assembly Bill VIII, as cited in Gangoli, 2006), and 70 percent are estimated to be HIV positive (Avert, 2006).

\subsection{Theoretical Background of the Study}

Feminist literature has extensively covered issues concerning sex work. Perceptions on validity and acceptance of sex work as a profession, attitudes toward sex workers and analysis of impact of sex work on society differ according to the type of feminist ideology utilized. Feminist positions on sex work are more or less divided into two distinct schools of thought: One group advocates the abolition of sex work and in doing so rejects the notion that women freely choose sex work. Marxist feminists, for instance fall into this category. Marxist feminists consider sex work a form of exploited labor with sex workers viewed as victims of the capitalistic system. The second group is the sex positive group, which propagates rights of sex workers. This group regards sex as a form of legitimate work or occupation and advocates for sex workers' right to equal opportunity (e.g., the sex workers' rights movements). The liberal and radical sexual pluralist feminists fall into this category. Liberal feminist theory views sex work as a profession, just as any other profession or work. Liberal feminists advocate for decriminalization of sex workers and consider the prohibition of sex work an interference with the individual's right to control her own body.

Radical sexual pluralist feminists share the same viewpoint about sex work but go one step further in advocating for the legalization of sex work. Radical sexual pluralist feminists believe that sex work is legitimate work, and by providing legal protection to sex workers, they believe criminal aspects can be controlled. Radical sexual pluralist feminists are different from liberal feminists as they emphasize understanding by listening to sex workers' voices and stories. They value sex workers' responses and opinions rather than outsiders' perspectives regarding constructing knowledge. Radical sexual pluralist feminists do not dichotomize sex workers into good and bad, right and wrong, and they view the sex industry through the lens of the sex workers themselves. Sex workers are considered experts in their field (Sloan \& Wahab, 2000; Wahab, 2002; Krumer-Nevo, 2009).

Our understanding about sex work has evolved over the course of time from personal experiences of interacting with sex workers in Mumbai to studying feminist theories on sex workers in the western world. We have closely witnessed the problems and difficulties of sex workers in India and have come to believe that criminalization of sex work, stigma and discrimination of sex workers in Indian society have marginalized and exploited sex workers. The political, economic and social status of sex workers in Indian society denies basic human 


\section{$\triangle$ Macrothink}

rights and social justice to sex workers. Examination of contemporary attitudes of policy makers and law-enforcers in India suggests that sex workers are considered criminals and are not protected by the law. Violence and abuse against sex workers is socially accepted and by virtue of their profession sex workers are considered to be on the "wrong side of the law". Taking this factor into consideration, we choose to be affiliated with the rights-based and radical sexual pluralist feminist approach for studying sex workers.

This approach has helped us in constructing this research on the following basis: 1) Sex workers have a voice of their own. This research study's methodology supports a dialogic and dialectical process which highlights the voices of sex workers and enumerates their experiences and stories. Sex workers are experts in their own lives who have a better understanding of violence and abuse they experience than any outsider/researcher; 2) Reality, for the purpose of this research, is relative and contextual. Reality is considered to be constructed and co-constructed by sex workers themselves during the course of research. This is in accordance with the radical sexual pluralist feminist approach which poses the importance of listening to the voices of those who have been "othered" in order to create their own reality (Sloan \& Wahab, 2000). Nature of knowledge is considered to be constructed with the help of interactions and subjective findings. Each sex worker interviewed for this research is considered a unique individual contributing to the knowledge base. 3) We agree with the radical sexual pluralist feminist standpoint of legalizing sex work, as we believe that legalization will protect sex workers. 4) This research is geared toward understanding experiences of violence and coercion among sex workers from a radical sexual pluralist feminist standpoint. Patriarchy and male domination as forms of exercising power over women will be used to explain violence and coercion in Kamathipura. Sex workers are viewed as active participants in the society. Oppression and gender-based discrimination are examined. We support the rights of women and the importance of prosecuting those who perpetuate violence and coercion.

\section{Literature Review}

\subsection{Gender-Based Violence Against Commercial Sex Workers}

Gender-based violence among sex workers is well researched and documented. Researchers have attempted to identify forms and severity of violence and have identified gender-based violence as an important factor contributing to HIV risk behaviors. In a quantitative study of 113 female sex workers from New York that explored partner violence, substance abuse, history of child sexual abuse and HIV risks, the researchers identified partner abuse to be a common occurrence among the street sex worker sample (El-Bassel et al., 2001). Two out of three street-based prostitutes were found to have experienced lifetime physical or sexual abuse by either an intimate or commercial partner. This study reinforces the intensity of violence committed against sex workers. Studies have found that sex workers may experience several forms of violence from pimps, partners, clients and police officers, ranging from physical violence to sexual assault (Dalla, Xia, \& Kennedy, 2003; Sanders, 2004). In countries like India where sex work is illegal and sex workers are stigmatized and labeled as 'immoral', sex workers are afraid of reporting crime to the police for fear of being arrested 
and re-victimized.

Space or location for soliciting sex is considered an important determining factor for degree and severity of violence. Raphael and Shapiro (2004) found a difference in frequency and severity of violence among brothel-based and street-based sex workers. Brothel-based sex workers reported frequent encounters of physical violence; however, street-based sex workers reported more severe incidences of sexual violence and the use of weapons. The researchers concluded that sex workers in any setting are subjected to violence and argued against the popular belief that brothel-based sex work is harm-free. The reason for such high rates of violence could be attributed to the inherent nature of sex work: being an unequal relationship between a man and woman and the view that women are considered objects of abuse and are freely coerced. Rape and sexual assault of sex workers is assumed to be acceptable due to the nature of their profession (Pauw \& Brener, 2003).

\subsection{Gender-Based Violence \& HIV Risks in Commercial Sex Workers}

Research has also highlighted the relationship between violence and HIV/AIDS among commercial sex workers. Researchers have focused on exploring connections between violence and HIV risk behaviors among sex workers in countries with high prevalence of HIV/AIDS and sex work (Dalla \& Kennedy, 2003; MacPhail \& Campbell, 2001; Marten, 2005; Pauw \& Brener, 2003; Wechsberg \& Lam, 2005; Wojcicki \& Malala, 2001). Researchers have also noted that exposure to violence increases the vulnerability of commercial sex workers to HIV related risk behaviors. Pauw and Brener (2003) identified barriers to HIV risk reduction among sex workers in Cape Town. Among other barriers, client violence, forced unprotected sex, police violence and lack of protection of commercial sex workers were identified as important factors associated with increased vulnerability to HIV/AIDS. Pauw and Brener (2003) also pointed out that the role of partners and regular clients in determining condom use, as well as client resistance to condom use are important barriers to HIV risk reduction. In the context of sex work, the responsibility of HIV prevention is placed entirely on the individual sex worker. HIV prevention interventions focus mainly on 'empowering' sex workers but clients' attitudes and resistance to condom use is not discussed. In doing so, sex workers continue to be blamed for spreading HIV infection, they continue to be labeled as vectors of HIV infection and the burden of 'saving' the man and his family from HIV infection rests in the hands of a sex worker.

\section{Purpose of the Study}

The above review of literature indicates consensus that gender-based violence makes it difficult for sex workers to negotiate safe sex thereby increasing their vulnerability to HIV infection. Just like substance abuse, gender-based violence is identified as an important barrier to HIV prevention in the red-light area. However, most of the studies available for review were conducted in developed countries or in Africa. Therefore, the literature review indicates a need to study gender-based violence and HIV risk behaviors in the Indian setting, where such research has not been conducted.

Moreover, the majority of available studies on gender-based violence and HIV risk among 
commercial sex workers were quantitative in nature and used structured or semi-structured interviews and questionnaires to study violence (Bassel et al., 2001; Marten, 2005; Pauw \& Brener, 2003; Raphael \& Shapiro, 2004; Wechsberg \& Lam, 2005; Wojcicki \& Malala, 2001). As a result of the very nature of quantitative methods, previous research used scales to measure violence, with definitions of violence created prior to data collection. The present research study, being qualitative in nature, did not narrow constructs by defining them but broadened the scope by exploring violence according to the field realties and responses.

The qualitative nature of the proposed study explored the process of exploitation and abuse that forces sex workers to participate in risk behaviors. Three research questions guided this research study: 1) How do commercial sex workers in Kamathipura, Mumbai, define and explain violence in their day-to-day lives? 2) How do commercial sex workers in Kamathipura, Mumbai, understand coercion in their day-to-day lives? 3) What do sex workers in Kamathipura, Mumbai, identify as consequences of violence in their daily lives?

\section{Methods}

\subsection{Procedure \& Participants}

This qualitative study was conducted during the two-month period from May 5, 2006 to June 30, 2006. The population of interest for the study was female commercial sex workers from Kamathipura, Mumbai, and in-depth interviews were used to gather data. The study was executed in collaboration with a social work organization in India named Prerana. Prerana facilitated the recruitment of participants by introducing the author(s) to the sex workers through community and home-visits. They also provided space in their office/center premises for conducting the interviews. Also, this research project was conducted in collaboration with the Tata Institute of Social Sciences (TISS), a social research institute based in Mumbai. The women's studies department of TISS funded the research and provided technical assistance. Twenty-five sex workers were recruited to participate in the study of which ten women agreed to be interviewed.

The project used informed consent and confidentiality norms laid down by the TISS research guidelines and, since the project was undertaken as a project by TISS, the ethical standards recommended by TISS were followed. The participants were provided with information about the research project and were told that they could drop out of the interview at any point if they did not wish to continue. Oral consent was considered appropriate to proceed with the research since the participants were not literate and, therefore, no written consent was obtained. Five interviews were tape-recorded and five were not, per participant's preference. All research participants were given pseudo names for this manuscript. The average interview lasted approximately an hour and a half with a maximum duration of two hours. The interviews were conducted for almost five weeks from mid-May until the end of June 2006.

\subsection{Data Collection Method}

An interview guide with several open and closed-ended questions was used to elicit the daily experiences of sex workers living in Kamathipura, Mumbai, India. The interview guide included: sex workers' demographics (e.g., age, marital status, number of children, education); 
information regarding their relationships with other members involved in the sex industry (i.e., clients, intimate partners, pimps, and police); specific questions regarding experiences with violence (i.e., physical, sexual, emotional); risky sexual behaviors (e.g., condom use, unprotected anal sex, exchanging sex for drugs or alcohol); drug and alcohol use (by sex worker and other members); and health (i.e., physical, mental, sexually transmitted infections (STI), and HIV/AIDS). The interview guide was translated to Hindi and Marathi for the purpose of facilitating the interviews. Data was translated from Hindi and Marathi to English.

\subsection{Analysis}

For the purpose of analysis, each interview was transcribed and re-written in the form of a narrative. Each narrative had quotes and dialogues from the interview and captured the voice and language of sex workers directly from the field. While writing the narratives, the first author also made memos (personal impressions and interpretations) of the interviews and recorded them separately from the actual narrative. This helped in maintaining credibility and ensured that the voice of the researcher could be separated from the voice of the participant. The narratives were also read by peers from TISS. The continuous dialogue with faculty from TISS and social workers from Prerana ensured peer briefing thereby maintaining conformability of the research methods. As the first author was writing the narratives, common themes and stories emerged. The first author also noticed that one out of the ten sex workers interviewed was an outlier who did not have any common elements with the others. This exception was also regarded as important and her impressions and experiences of being able to live 'violence free' have been reported in the analysis.

This research study was also analyzed from a radical sexual pluralist feminist standpoint. Ways in which patriarchy perpetuates violence against sex workers will be discussed with the help of narratives and descriptions provided by sex workers. As well, power dynamics in the red-light area will be explored. Radical sexual pluralist feminists view the perpetration of violence to be associated with inequality between the men (clients/partners) and women (sex workers) due to gender differences. Patriarchal behaviors of controlling women (e.g., asserting pressure until a desired behavior is displayed) and objectification of women can be attributed to violence among sex workers. The underground nature of sex work not only perpetuates violence but also encourages it. The radical sexual pluralist feminist viewpoint holds that keeping sex work illegal is a form of systemic and structural discrimination against sex workers and a way in which the male dominated society attempts to curb sexual freedom of women to practice sex work.

Although several themes emerged from the interviews, for the purpose of this research, we would like to discuss three themes that are consistent with the research questions posed in this paper. These themes are: 1) Experiences of coercion and violence among sex workers, 2) Manifestations of patriarchy: from client to partner to pimp, and 3) Outcomes of violence and coercion among commercial sex workers. Each theme is supported by quotes from the narratives and is followed by personal and theoretical interpretation of the theme. 


\section{Results}

\subsection{Experiences of Coercion \& Violence Among Sex Workers}

Although manifestations of coercion were narrated differently between sex workers based on their personal and unique experiences, sexual and economic coercion seemed to be an underlying reality in the lives of all the sex workers. There was a thin line of distinction between coercion and actual physical and sexual violence. Coercion preceded violence and was subtle yet intense and more sustained than acts of actual physical and sexual violence.

In every narrative, sex workers reported that partners, pimps, and clients committed sexual, physical and emotional violence against them. One example of this was given by Rani who stated that her partner, who was extremely jealous, had kicked her in the stomach while she was pregnant, causing immense bleeding. However, sex workers rarely filed complaints of violence with the police, as the sex workers often were imprisoned for practicing sex work and/or were abused by the police. Saira recalled a situation where she was arrested in a police roundup:

The hawaldar (policeman) slapped me and arrested me; he took me to the police station. When I went there I told the inspector (head of police staff) that I was slapped and verbally abused by his policeman...but the inspector also verbally abused me and said that I am fit to be kicked as I am doing wrong. I told them that I have small children and if I don't stand on the road I would be unable to feed my family but they abused more and said I should go back to my village in Bangladesh.

Sexual coercion was the most common form of violence reported by sex workers and it usually took the form of a partner demanding sex. Sex workers were threatened with physical violence by the intimate partner if they did not comply. Saira described the consequence for her non-compliance to her intimate partner's demands for sex: "He takes drugs and asks for sex and I hate that. He beats me because of this". Another sex worker, Soni, shared a similar story about her intimate partner "He would force me to have sex with him. He would beat me and kick me if I refused to have sex with him".

Sexual coercion came from a variety of individuals in the sex worker's life, including family members. For example, Saira was sold into sex work when she was 10 years old by her aunt. She stated:

My aunt was a brothel-owner. She took me with her to her brothel and at 10 I started earning from sex work. My first intercourse was very painful. My customer were very old and big. I did not know the meaning of sex and rape before. After starting sex work I not only understood its meaning I also experienced it several times every night. Every intercourse was forced. I spent hours crying over my fate but my aunt did not give any consideration.

Economic coercion was also a commonly observed theme among all sex workers. Intimate partners took upon roles of pimps in the intimate relationship and demanded control of the sex worker's professional choices. Intimate partners controlled the number of clients the sex 
worker should take and took charge of handling accounts for the sex worker. In doing so, sex workers lost their freedom to choose clients and did not have access to the income they earned. Sex workers were forced to take more clients than they wanted and were monitored by intimate partners to make sure they do not provide additional services for free. An example of this was seen in the case of Saira. She reported:

He would take away all the money I earned and did not give me any money for personal expenses. He was very violent and would get angry and beat me for some reason or the other. He would supply clients to me and if I took even five minutes more with a client, he would break into a fight.

The conflicting roles of pimp and intimate partner inevitably led to violence. Rani provided an example of how the role of an intimate partner conflicted with the role of pimp, which eventually led to violence:
After one year of marriage, I was pregnant with his child. However, he suspected that the child was not his but of another client who visited me regularly. I could not prove to him that it was his child and we broke into arguments very frequently. I was also very sick during the time of my pregnancy. I was weak and the doctors had advised that I should take complete rest. My partner however, did not listen to the doctors and he forced me to take clients 'til I was almost seven months pregnant and even though I was against it, with the hope of avoiding conflict, I did as he wished. Violence and suspicion was integral to our marriage and I had gotten used to it. I never retaliated.

The above example reveals how partners who became pimps forced sex workers to take more clients in order to get a higher income; however, they also suspected the sex workers and abused them as a result of presumed infidelity. In this example, the sex worker complied with the partner's demands to avoid the violence she had experienced in the past.

\subsection{Manifestations of Patriarchy: From Client to Partner to Pimp}

The narratives indicate that there was a pattern to the transition in the relationship between the sex worker and her intimate partner. The majority of sex workers reported that their current intimate partner was initially their client who had gradually become a regular client showing special preference and interest in the sex worker. Once the client became a regular, the client got special privileges (e.g, free services, gift exchanges, more time than average) from the sex worker and gradually the relationship changed form a professional to a personal one. Sex workers reported falling in love with regular clients, which eventually resulted in marriage and cohabitation. One of the sex workers, Lata, narrated this transition.

She said:

He was my client but unlike other clients he spent more time with me and came to me daily. Sometimes he slept with me. He asked me questions about my life and my background. It seemed like he took interest in me. I had no close relationships and he seemed like my only support system. He promised to rescue me from the red-light area and offered to marry me. After some days, he helped me escape from my 
brothel owner. I married him with the hope that I would leave sex work forever. However, that was not his real intention...

The above example explains how a client transitioned to a regular client and eventually a husband. Regular clients often showed sympathy toward the sex workers and promised the sex workers better lives if they agreed to marry and live with them. Some of the sex workers were even taken away from the red-light area briefly after marrying the clients. However, five of the ten sex workers interviewed reported returning to the red-light area after being 'rescued' because of circumstances beyond their control. Soni is one such sex worker who reported returning to Kamathipura after being "rescued" by her husband. This return to Kamathipura also meant a return to sex work.

He introduced me to his family, we were far away from Mumbai and I had decided to forget my past, live a new life as a 'normal' woman. However, I was not lucky; I suffered from Tuberculosis and fell very sick. My in-laws suspected me and after looking at my health condition refused to take care of me. We had to return to Mumbai and we started living in Kamathipura again. He asked me to start sex work again as he did not have a job. He promised to relieve me of sex work as soon as he could get a job. It's been more than 10 years now; I am still a sex worker.

Another transition reported by the sex workers was that of husbands or intimate partners taking on the role of pimp. The majority of the sex workers reported that their partners were indeed their pimps who controlled their decisions, both personally and professionally. Rani explained this transition in the following way:

After he started living with me, he left his job of a taxi driver. He said he wanted to help me. He told me that he would provide me with good clients and that way both of us would make more money. I did not realize it then but with this agreement, I had lost all my freedom. I had to do what he said. He forced me to have sex in the daytime and did not give me any money that I earned. He had become my pimp.

From client to partner to pimp, most of the sex workers reported the transition of client to partner to pimp, unaware that the process was even occurring. Most of the sex workers reported that their need for love, acceptance, stability, companionship and legitimacy were driving forces for marriage and cohabitation. Although each individual sex worker's experience of violence and exploitation varied from the other, it converged at some level into a common pattern of regret, unhappiness and discontent over their personal situation. The only sex worker, who was an exception to this was Raveena. She said:

I know how it works. Many of them ask me for marriage, but I refuse. To me sex work is just a business. I don't trust men here so I don't have any partners. All women who get beaten up have partners who beat them. They get fucked and beaten up. I don't want to be one of them. No one beats me. I am alone, I am happy.

Although Raveena had a strategy to prevent violence (i.e., not having an intimate partner), she later reported that she was unsure of how long she could indeed live alone. Therefore, it is clear that living alone is not the real solution. The problem is deep-rooted and is situated in 
the underlying social belief that sex workers are objects to abuse. The women are bought and sold and, thus, can be exploited and taken advantage of. Their voice is rarely heard and has no relevance in the society. Sex workers are often blamed for being unprofessional if they have emotional/love relationships with clients. For example, sex workers reported that the police blamed them for having partners instead of helping them when they reported violence.

Sex workers in this research clearly stated that they need safe and secure means to solicit sex. They want the abuse from pimps and partners to stop, as well as their complaints to be heard by law enforcers and policy makers. They want economic exploitation to cease and control over their income. They demand equal rights alongside women in the 'general' population and demand acceptance of their profession so that they can solicit safely and securely without threat from the police.

\subsection{Consequences of Violence \& Coercion Among Commercial Sex Workers}

Sex workers did not make a distinction in describing outcomes of coercion and violence. They reported constant pressure and tension and reported feeling scared and insecure. Some of them reported having sleepless nights due to tension and reported that uncertainty about the future constantly worried them and affected their work and relationships. Almost all sex workers reported fear of their clients and pimps, while some reported feeling taken advantage of by their partners. They felt that their relationship did not involve love but was based on an agreement, which ended up making them more vulnerable and helpless. Radha, a 35-year-old sex worker elaborated her feeling of fear and anxiety. She explained her worries and the consequences her anxiety had on her day-to-day life:

He left me and took my boys (two sons) with him. It's been five years. I wonder how my children are and I worry about them. I am afraid to go to his city to search for my boys as I feel if he sees me again he will kill me. I don't know my HIV status but I am sure I am clean. I am scared about it though. What if my children too.... I don't know. I keep thinking all the time. I don't feel hungry and can't sleep properly. Should I get a HIV test done... but I am not sure how it will help me. All have to die eventually. Kamathipura anyway has no business now. For old sex workers like me there is no money and no hope. Police rule this place and if you are young and attractive the police also spare you and don't catch you.

Like Radha, many sex workers in Kamathipura were confused and scared to know their HIV status. They were worried that if they were detected seropositive, they would be out of business. The health care facilities do not support HIV infected sex workers adequately and sex workers often choose to live on subsistence rather than planning for the future (Kamathipura, Prerana staff, personal communication, May 15, 2006).

Sex workers also suffer from a variety of serious physical and mental health problems, such as depression, substance abuse, and suicide attempts, as a result of harsh and cruel beatings and rape. Violence against sex workers was explicitly reported in the narratives, often accompanied by very severe and serious consequences. Lata, for instance, reported severe violence from her current pimp/partner. She narrated a recent violent episode with her partner 
who had recently pushed her to the ground and kicked her on the stomach and back. He then got a chain and beat her with it. She was bleeding profusely and had to be rushed to the hospital. Additionally, Mona described the violence that occurs in Kamathipura and its effect on sex workers:

If you look closely inside Kamathipura you will see women crying over their ill fate. Some are beaten up and tortured, some are sick; some have bruises and swollen muscles. But I think all of us are scared to die and that's why we keep on living. There is sadness all around. All men here depend on woman's money and yet, the woman is powerless.

The sadness described by Mona is a common trend among the participants. Some participants often wondered if it would be better to be dead than to survive in such a ruthless and unforgiving environment. Substance abuse was used to cope with life and dull everyday pain. Rani said:

I was unable to pay the room rent...we are living on the street. He gave me a lot of mental tension. Sex work suffered as I was unable to look attractive. Sex work is short-lived and I had no other skill or source of income. I started drinking again to forget the pain and lost my beauty and charm. I have scars all over my body and have tried to cut my nerves many times, but I don't know why God has saved me. I know that I am HIV positive. I try not to drink but I can't control the urge. It helps me live.

Intimate partners also used alcohol to manipulate situations. Sex workers' narratives described perpetrators were often drunk before a violent episode. Additionally, intimate partners lured sex workers with alcohol to get sexual favors and/or money and to make sex workers take more clients than they wanted.

\section{Discussion}

The results of this study indicate the intensity and severity of coercion and violence in the red-light area of Kamathipura. The sex workers' experiences of being forced and controlled by their male partners were clearly heard in the narratives. Sex workers reported being physically and mentally harassed and many of them expressed anxiety about their safety and security in the red-light area. The majority of the sex workers interviewed for this research were HIV positive and all of them expressed anxiety about the illness. Additionally, the majority of sex workers reported not using condoms while having sex with their intimate partners, while more than half of the sex workers reported being casual about using condoms with clients. The narratives indicated dominance by male partners and that sexual decision-making was a male prerogative. Men decided whether or not condoms were used in intimate partner relationships and partners/pimps made decisions about whether sex workers should take their clients with or without condoms. Most often resistance to male partners' demands resulted in violence and many sex workers reported giving in to demands in order to avoid violence. Sex workers reported an inability to negotiate safe sex, and the majority felt powerless in their relationship even though they were the primary breadwinners. 
Patriarchy was also manifested in the process of male transition from client to intimate partner to pimp. Men exploited their dual status of partner and pimp to gain sexual and financial benefits from the relationships. This pattern seemed to be integral with sex workers' life cycle in Kamathipura. The pattern also seemed to be structural. It is sustained over a number of years and is perpetuated and encouraged by the male dominated societal structures in which Kamathipura is contextually situated. Kamathipura in the context of the larger Indian society is regarded as a "necessary social evil". On one hand, a red-light area such as Kamathipura is regarded as degrading and immoral, and sex work is labeled a social evil that needs to be eliminated and destroyed. On the other hand, sex work is deemed necessary for society, as sex work's absence will result in women from "normal" families being raped and molested. Thus, the red-light area must exist to quench increasing male sexual desires. As seen in the research, women do not have decision-making power; they are roped into a system, the rules of which are constructed by men.

Although the consequences of violence are severe, violence in Kamathipura is still not considered an important problem. In India, sex work is deemed illegal and immoral as per the constitution. Most of the government efforts are geared toward the rescue and rehabilitation of sex workers, and most of the private organizations work on HIV prevention with no inclusion content around violence and inter-personal relationships. Safety and protection of sex workers is, in a way, unlawful as it means indirectly promoting the sex trade. Police perform the role of threatening and arresting sex workers and fail to punish perpetrators if violence is ever reported. Patriarchy in Kamathipura is not just seen as an act of violence by male partners, but is also seen as inherent to the political and legal system, which does not institute laws to safeguard women. The political and legal system has unjustly panelized sex workers over decades. Sex workers express displeasure over police action and raids and complain that the police blame them rather than help them. Sex workers do not regard legal help as an option for their protection against violence and suggest alternative safeguards such as help from private organizations or escaping from violence to ensure their safety.

\section{Conclusions}

Although patriarchy is universal, manifestations of it differ in intensity and severity across different situations and cultures. In the red-light area of Kamathipura, patriarchy, male-domination and objectification of women were seen blatantly. Young girls (majority were minors) were sold into sex work. The majority of sex workers were unwilling to join the industry but got involved due to the poor financial conditions of their native families. Most sex workers joined the profession out of necessity, yet they were continually blamed by society for being immoral. Sex workers reported being stigmatized by the police and law makers, and they reported being ill treated by the medical/health workers. They did not view rehabilitation as a possibility, because they had always been regarded as "soiled" women. The aid to sex workers came from social workers who operated on principles of charity or who showed sympathy and pity toward sex workers.

Most of the organizations in Kamathipura are based on the principle that sex work is exploitative and sex workers need to be rescued. Sex workers' voices are rarely heard and 
there is comparatively little field effort to enforce sex workers' rights in Kamathipura. The research indicates the need for a field-based radical sexual pluralist feminist initiative to stop violence and ensure safety and protection of sex workers. The research also emphasized the need for sex workers to decide whether or not they wished to continue with the profession rather than blanket criminalization of all sex workers. Sex workers should be allowed to exercise their choice and should be given control over their income and resources. Such a change may not be possible without effective policy change to decriminalize and legalize sex work. Such policy change will ensure that sex work is treated just as any other profession with hopefully a reduction in ill-treatment and exploitation.

\section{References}

AVERT. (2005). HIV/AIDS in India. [Online] Available: http://www.avert.org/aidsindia.htm (September 19, 2005)

Bullough, V., \& Bullough. (1987). Women \& prostitution. Buffalo, NY: Prometheus Bks.

Chattopadhyay, A., \& McKaig, R. G. (2004). Social development of commercial sex workers in India: An essential step in HIV/AIDS prevention. AIDS Patient Care \& STDs, 18(3), 159-168. http://dx.doi.org/10.1089/108729104322994847

Dalla, R., \& Kennedy, H. (2003). "You just give them what they want and pray they don't kill you" street-level sex workers' reports of victimization, personal resources, and coping strategies. Violence Against Women, 1367-1394. http://dx.doi.org/10.1177/1077801203255679

Dunkle, K. L., Jewkes, R. K., Brown, H. C., Gray, G. E., McIntyre, J. A., \& Harlow, S. D. (2004). Gender-based violence, relationship power, and risk of HIV infection in women attending antenatal clinics in South Africa. Lancet, 363(9419), 1415-1421. http://dx.doi.org/10.1016/S0140-6736(04)16098-4

El-Bassel, N., Gilbert, L., Wu, E., Hyun Go, \& Hill, J. (2005). HIV and intimate partner violence among methadone-maintained women in New York City. Social Science \& Medicine, 61(1), 171-183. http://dx.doi.org/10.1016/j.socscimed.2004.11.035

El-Bassel, N., Witte, S. S., Wada, T., Gilbert, L., \& Wallace, J. (2001). Correlates of partner violence among female street-based sex workers: Substance abuse, history of childhood abuse, and HIV risks. AIDS Patient Care \& STDs, 15(1), 41-51. http://dx.doi.org/10.1089/108729101460092

Gangoli, G. (2006). Silence hurt and choice: Attitudes to prostitution in India and the west. London School of Economics.

Krumer-Nevo, M. (2009). From voice to knowledge: Feminism and participatory action research. International Journal of Qualitative Studies in Education, 22(3), 279-296. http://dx.doi.org/10.1080/09518390902835462

MacPhail, C., \& Campbell, C. (2001). I think condoms are good but, Aai, I hate those things: condom use among adolescents and young people in South African township. Social Science 


\section{Macrothink}

International Journal of Social Work ISSN 2332-7278 2014, Vol. 1, No. 1

\& Medicine, 52(11), 1613-1627. http://dx.doi.org/10.1016/S0277-9536(00)00272-0

Marten, L. (2005). Commercial sex workers: Victims, vectors or fighters of the HIV epidemic in Cambodia? Asia Pacific Viewpoint, 46(1), 21-34. http://dx.doi.org/10.1111/j.1467-8373.2005.00257.x

Pauw, I., \& Brener. (2003). You are just whores-you can be raped: Barriers to safer sex practices among women street sex workers in cape town. Culture, Health \& Sexuality, 5(6), 465-481. http://dx.doi.org/10.1080/136910501185198

Raphael, J., \& Shapiro, D. L. (2004). Violence in indoor and outdoor prostitution venues. Violence Against Women, 10(2), 126-139. http://dx.doi.org/10.1177/1077801203260529

Sanders, T. (2004). The risks of street prostitution: Punters, police and protesters. Urban Studies, 41(9), 1703-1717. http://dx.doi.org/10.1080/0042098042000243110

Sloan, L., \& Wahab, S. (2000). Feminist voices on sex work: Implications for social work. Affilia: Journal of Women \& Social Work, 15(4), 457-479. http://dx.doi.org/10.1177/088610990001500402

UNAIDS 2004. (2005). Report on global AIDS epidemic. [Online] Available: from http://www.unaids.org/bangkok2004/GAR2004_html/ExecSummary_en/Execsumm_en.pdf (September 16, 2005)

Wahab, S. (2002). For their own good?: Sex work, social control and social workers, a historical perspective. Journal of Sociology \& Social Welfare, 29(4), 39-57.

Wechsberg, W. M., Luseno, W. K., \& Lam, W. K. (2005). Violence against substanceabusing South African sex workers: Intersection with culture and HIV risk. AIDS Care, 17(s1), 55-64.

Wojcicki, J. M., \& Malala, J. (2001). Condom use, power and HIV/AIDS risk: Sex-workers bargain for survival in Hillbrow/Joubert Park/Berea, Johannesburg. Social Science \& Medicine, 53(1), 99-121.

\section{Copyright Disclaimer}

Copyright reserved by the author(s).

This article is an open-access article distributed under the terms and conditions of the Creative Commons Attribution license (http://creativecommons.org/licenses/by/3.0/). 